$\xi=$ 国

\title{
Modeling and Analysis of Micro Gas Turbine Compressor Different Parts
}

\author{
Sinoj $^{1}$, M. Dev Anand ${ }^{2 *}$, N. Ramasamy ${ }^{3}$ \\ ${ }^{I}$ PG Student, Department of Mechanical Engineering, Noorul Islam Centre for Higher Education, Kumaracoil, Kanyakumari District, \\ Tamilnadu, India. \\ ${ }^{2}$ Professor and Dean, Department of Mechanical Engineering, Noorul Islam Centre for Higher Education, Kumaracoil, Kanyakumari \\ District, Tamilnadu, India. \\ ${ }^{3}$ Associate Professor, Noorul Islam Centre for Higher Education, Kumaracoil, Kanyakumari District, Tamilnadu, India. \\ *Corresponding author E-mail: anandpmt@ hotmail.com
}

\begin{abstract}
The work displayed in the report is an endeavor at planning a miniaturized scale turbine of a given measurement. Broad writing audit was done to contemplate the different perspectives and utilizations of small scale turbines. An appropriate outline methodology was looked over the accessible strategies to plan distinctive parts of miniaturized scale turbine. CATIA is utilized broadly to make parts with diff sorts of tasks. At that point every one of the parts are collected for making a total turbine in CATIA Get together area. At that point they are sending for fast prototyping.
\end{abstract}

Keyword: Modeling, Micro Gas Turbine, Compressor Different Parts

\section{Introduction}

Miniaturized scale turbines are little ignition turbines which are having yield extending from $20 \mathrm{~kW}$ to $500 \mathrm{~kW}$. The Advancement is from car and truck turbo chargers, assistant power units (APUs) for planes, and little stream motors. Miniaturized scale turbines are generally new dispersed age innovation which is utilized for stationary vitality age applications. Regularly they are burning turbine that produces both warmth and power on a moderately little scale.

\section{Literature review}

A turbine can be utilized as a refrigerant machine was first presented by Ruler Rayleigh. In a letter June 1898 to Nature, he proposed the utilization of turbine rather than a cylinder expander for air liquefaction in light of pragmatic challenges caused in the low temperature responding machines. He underlined the most imperative capacity of and cryogenic expander, or, in other words of the cool, as opposed to the power delivered.

In 1898 The English specialist Edgar C Thrupp licensed a basic melting framework utilizing an extension turbine. Thrupp's expander was a twofold stream machine entering the middle and isolating into two oppositely streaming streams.

A regenerative extension turbine with an unrelated internal stream design was protected by the Americans Charles F and Orrin J Crommett in 1914. Gas was to be admitted to the turbine wheel by a couple of spouts, yet it was indicated that any coveted quantities of spout could be utilized. The turbine cutting edges were bended to introduce marginally curved countenances to the fly from the spout. These cutting edges were relatively short, not surpassing near the rotor center point
In 1922, the American specialist and educator Harvey N Davis had protected an extension turbine of abnormal thermodynamic idea. This turbine was planned to have a few spout hinders each accepting a flood of gas from various temperature level of high weight side of the principle warm exchanger of a liquefaction mechanical assembly.

First fruitful business turbine created in Germany which utilize a hub stream single stage motivation machine. Later in the year 1936 it was supplanted by an internal outspread stream turbine dependent on a patent by an Italian creator, Guido Zerkowitz.

Work on the little gas bearing turbo expander initiated in the mid fifties by Sixsmith at Perusing College on a machine for a little air liquefaction plant. In 1958, the Unified Kingdom Nuclear Vitality Specialist built up a spiral internal stream turbine for a nitrogen generation plant. Amid 1958 to 1961 Stratos Division of Fairchild Air ship Co. fabricated blower stacked turbo expanders, for the most part for air division benefit. Vothet. Built up a rapid turbine expander as a piece of a chilly mediator cooler for the Argonne National Lab (ANL). The main business turbine utilizing helium was worked in 1964 of every a fridge that created $73 \mathrm{~W}$ at $3 \mathrm{~K}$ for the Rutherford helium bubble chamber. A fast turbo alternator was produced by General Electric Organization, New York in 1968; this kept running on a commonsense gas bearing framework fit for working at cryogenic temperature with low misfortune.

Yang et al., built up a two phase scaled down development turbine made for a 1.5 liters/hour helium liquefier at the Cryogenic Building Lab of the Chinese Institute of Sciences. The turbines pivoted at in excess of 500,000 rpm. The plan of a little, rapid turbo expander was taken up by the National Department of Models (NBS) USA. The main expander worked at $600,000 \mathrm{rpm}$ in remotely pressurized gas course. The turbo expander created by Kate et al., was with variable stream limit instrument (a movable 
turbine), which had the limit of controlling the refrigerating force by utilizing the variable spout vane tallness.

India has been lingering behind whatever is left of the world in this field of innovative work. In any case, critical advancement has been made amid the previous two decades. In CMERI Durgapur, Jadeja built up an internal stream outspread turbine bolstered on gas course for cryogenic plants. The gadget gave stable revolution at around 40,000rpm. The program was, be that as it may, stopped before any noteworthy advancement could be accomplished. Another program at IIT Kharagpur built up a turbo expander unit by utilizing aerostatic push and diary heading which had a working rate up to $80,000 \mathrm{rpm}$. As of late Cryogenic Innovation Division, BARC created Helium cooler equipped for delivering $1 \mathrm{~kW}$ at $20 \mathrm{~K}$ temperature.

Improvement of a stage fit for recreating the execution of gas turbines connected in street vehicles. The creator's effort centered around the advancement of two devices: an executable code equipped for making the efficiency guide of any gas turbine display, in view of information produced by business programming (GasTurb) that assesses the motor thermodynamic cycle for both outline and of-plan operational conditions.

The utilization of small scale turbine generators in cross breed electrical vehicles - Power prepares The record quickly depict a few thoughts for ultra-low discharge utilizing smaller scale turbine In an arrangement half breed configuration(HIL Tech improvement constrained)

Millimeter-Scale, MEMS Gas Turbine Motors Enhanced convenient gadgets with the quickly extending ability of micromachining innovation has made possible minimal power hotspots for the improvement of gas turbines in the millimetermeasure run. With airfoil traverses estimated in 100's of microns instead of meters, these "miniaturized scale motors" have around 1 millionth the wind current of vast gas turbines and accordingly should deliver around 1 millionth the power, 10-100W.

MEMS-Idea Utilizing Small scale Turbines for Satellite Power Supply These Power-MEMS will be utilized as an option in contrast to batteries for workstations, camcorders or other power devouring versatile applications. The examination gathering of Reynaerts (Branch of Mechanical Designing, College of Leuven, Belgium) (Peirs et al., 2003) has built up a Power-MEMS utilizing a solitary stage pivotal smaller scale turbine with a rotor distance across of $10 \mathrm{~mm}$ This turbine is an initial phase in the advancement of a miniaturized scale generator.

Improvement of a Synergist Smaller scale combustor For Hydrocarbon-filled Power MEMS This paper reports the advancement of a high proficiency, hydrocarbon-energized miniaturized scale burning framework for a small scale gas turbine motor for power age and miniaturized scale drive applications. A three-wafer synergist combustor was manufactured and tried. Efficiencies more than $40 \%$ were accomplished for ethylene-air and propane-air ignition.

Configuration Concentrate for Single Stage High Weight Turbine of Gas Turbine Motors, Ajoko, Tolumoye John - The exploration paper is an outline concentrate to diminish different phases of High Weight Turbine (HPT) to keep up a similar push - to weight proportion of gas turbines. This current methodology of gas turbine configuration is to lessen cost and weight of the part.

Miniaturized scale gas turbine arrangements with carbon catch e Execution appraisal utilizing an approved thermodynamic model Mohammad Mansouri et al., is exhibited. $\mathrm{CO} 2$ catch unit is coordinated to the benchmark MGT display. Small scale gas turbine utilizing EGR and Cap cycles with $\mathrm{CO} 2$ catch is additionally explored. Impacts of surrounding temperature minor departure from the cycles' execution are displayed. A significant change in cycle productivity for the Cap cycle is appeared.

Life investigation of modern gas turbines utilized as a back-up to inexhaustible the assessed life of gas turbines is relied upon to lessen after some time when contrasted with the makers' evaluated life, especially when utilized as a back-up to Sustainable power Sources (RES). As RES are been brought into the lattice, the gas turbines utilized related to them are worked in "Load-Following" modes to these RES which incorporates wind, warm, sun powered, and so forth.

Small scale gas turbine based test fix for cross breed framework copying - the thermo concoction control gathering (TPG) is working at the research center of the college of genoa, italy, another high temperature energy unit - miniaturized scale gas turbine physical emulator dependent on business machine innovation.

Accomplishing hub equalization of a small scale turbine rotor with low bearing weights for start-up and fast task - adaptation of the weight field around a $4 \mathrm{~mm}$ distance across rotor of a smaller scale turbine was done to see the cooperation between the segments (multistage miniaturized scale turbine, winding furrow gooey seals and pump, hydrostatic direction) and their effect on pivotal power and solidness to accomplish low push bearing hub balance.

\section{Development of model}

\subsection{General procedure adopted for modeling the micro turbine}

PRO/E Part Application

1. Datum planes

2. Pad, Pocket - Extrude

3. Edge Fillet

4. Holes

\begin{tabular}{|l|l|l|}
\hline \multicolumn{3}{|l|}{ Table l: Compressor Geometry Parameter } \\
\hline Items & Parameter & Value \\
\hline Shaft Diameter & $\mathrm{D}(\mathrm{mm})$ & 20 \\
\hline Impeller Inner Diameter & $\mathrm{D},(\mathrm{mm})$ & 55 \\
\hline Impeller Outer Diameter & $\mathrm{D}_{2}(\mathrm{~mm})$ & 136 \\
\hline Impeller Thickness to Shaft & $\mathrm{h}(\mathrm{mm})$ & 42 \\
\hline Impeller Outflow Thicknes & $\mathrm{b}(\mathrm{mm})$ & 4.825 \\
\hline Blade Degree & $\boldsymbol{\beta}($ degree $)$ & 23.20 \\
\hline Blade Number & - & 16 \\
\hline
\end{tabular}

\subsection{Build geometry in CATIA}

Step 1: 2d Sketch has been Drawn Using Component Drawing.

i. $\quad$ Start $>$ mechanical design $>$ sketcher.

ii. In the sketcher work bench $2 \mathrm{~d}$ drawing has been drawn using different sketch. Tools like line, circle, spline, arc, fillet etc, as per component drawing.

Step 2: Shaft Option is Used to Revolve the 2D Sketch in to Part Design of Disc.

i. After exiting sketcher workbench select the part design

ii. Select the shaft option

iii. Revolve the $2 \mathrm{~d}$ sketch with respect to $\mathrm{x}$ axis.

Step 3: 2d sketch's of blade has been imported and joined by combine solid option.

i. $\quad \mathrm{X}$,yand $\mathrm{z}$ co ordinates of an aero foil has been taken in notepad and imported to CATIA.

ii. Similarly seven aerofoil's has been imported.

iii. Using solid combine option all the seven aerofoil's are combined to form a blade.

Step 4: Circular pattern option is used to make one blade to 42 blades.

Step 5: Fillet radius between the blade and the disc is increased from 4.5

i. in the part design workbench fillet option is selected 
ii. radius $4.5 \mathrm{~mm}$ is given at the root of the blade

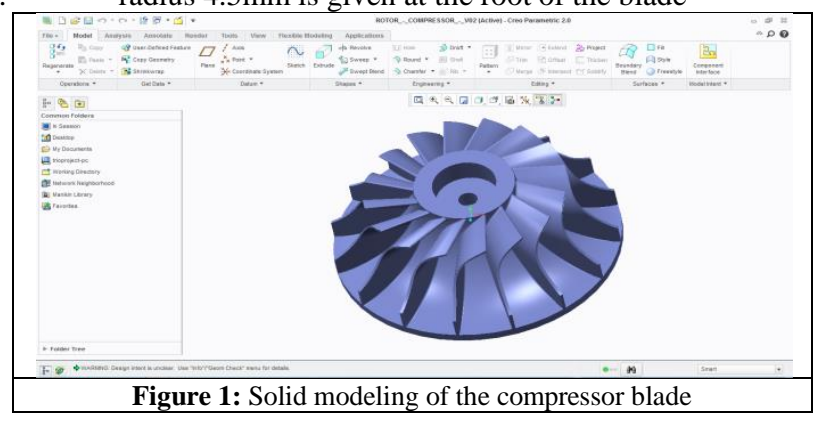

\section{Finite element analysis}

It is not possible to obtain analytical solution for many engineering problems. At the engineering solution is a mathematical model or expression that gives the value of the field variable at any location in the body.

\subsection{Mathematical background}

ANSYS creates differential equations on each element. These equations are called as elementary equations. In ANSYS the law of conservation of mass was used for pressure and momentum principle for velocity and energy principles for temperature.

\subsection{ANSYS}

Generally extremely confused models are demonstrated in Master/E V5 and after that foreign made in ANSYS programming. IGES choice is utilized for this reason. IGES implies Introductory Illustrations Trade Particular. This is a standard configuration for exchanging computer aided design documents from one to the next. The 4 stroke cylinder displayed in Star/E V5 is transported in to ANSYS utilizing this alternative.

\subsection{Methodology utilized in ANSYS}

The ANSYS program has numerous limited component investigation abilities, going from a basic, straight, static examination to an intricate, nonlinear, transient powerful investigation. The examination control manuals in the ANSYS documentation set portray particular strategies for performing investigations for various building disciplines. The following couple of areas of this part cover general advances that are regular to generally examinations

\subsection{A typical ANSYS analysis has three distinct steps}

\section{Step 1: Mesh the Volume}

i. $\quad$ Main Menu $>$ Preprocessor $>$ Meshing $>$ Mesh Tool

ii. Choose Manual Size Controls, you simply specify a mesh size level from 1 (fine mesh) to 10 (coarse mesh). Select free mesh and press $\mathrm{OK}$

Step 2: Apply Inertial Load

MainMenu $>$ Preprocessor $>$ Loads $>$ DefineLoads $>$ Apply $>$ Structural $>$ Inertia $>$ Angul-ar Velocity $>$ Global $>$ Omeg $>$ Enter the value on the correct axis $(\mathrm{X}, \mathrm{Y}, \mathrm{Z})$.

Step 3: Apply Boundary Condition

Main Menup Solution $>$ DefineLoads $>$ Apply $\Rightarrow$ Structural $>$ Displacement $>$ On Areas $>$ Select the Areas.

Main Menu> Solution $>$ Define Loads $>$ Apply $>$ Structural $>$ Displacement $>$ Symmetry B.C $>$ On Areas $>$ Select the symmetrical areas.
Step 4: Thermal Analysis

Obtain Solution

Step 5: Solve Main Menu > Solution > Solve > Current LS

i. Review the information in the Status Window, then choose File $>$ Close (Windows) or Close(X11/motif), to close the window.

ii. $\mathrm{OK}$ to begin the solution.

iii. Choose yes to any Verify message that appears.

v. Close the information window when the solution is done.

Review Results

Step 6: Plot the Deformed Shape

i. Main menu > General Postproc > Plot Result > Deformed Shape

ii. Choose Def + Unreformed

iii. $\mathrm{OK}$

iv. You can also produce an animated version of the deformed shape.

v. Utility Menu > Plot Controls > Animate > Deformed Shape

vi. Choose Def + Unreformed

vii. $\mathrm{OK}$

Step 7: Plot the von Misses equivalent stress

i. Main Menu > General Post process > Plot Result > Contour Plot > Nodal Solution.

ii. Choose Stress item to be contoured.

iii. Scroll down and choose von Misses (SEQV).

iv. $\mathrm{OK}$

v. You can also produce an animated version of these results.

a. Utility Menu > Plot Controls > Animate > Deformed Results.

vi. Choose Stress item to be contoured.

vii. Scroll down and choose von Misses (SEQV).

viii. OK.

Step 8: Exit the ANSYS Program

i. When leaving the ANSYS program, you can spare the geometry and load parts of the database (Default), spare geometry, burdens and arrangement information, and post preparing information (i.e. spare everything), or spare nothing. You can spare nothing here except for you ought to make sure to utilize one of the other spare alternatives in the event that you need to keep the ANSYS information documents. Tool bar : Quit

ii. Choose Quit- load + geom.

iii. $\mathrm{OK}$

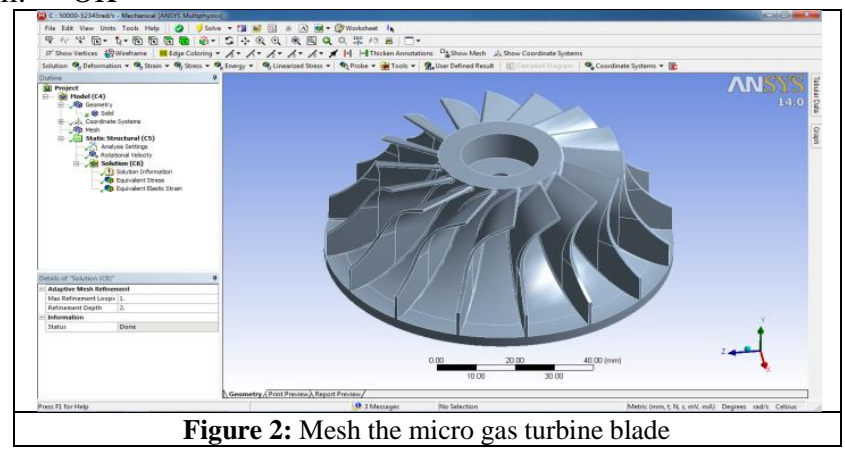

The objective of this study is to model a micro turbine compressor blade and conduct stress analysis as well as vibration analysis based on its rotation per minutes.

\subsection{Materials}

- Aluminum Alloy

- Stainless Steel Alloy

- Titanium Alloy 


\subsection{Rotational speed}

- $40000 \mathrm{rpm}$

- $\quad 50000 \mathrm{rpm}$

- $60000 \mathrm{rpm}$

The outline and the examination of the structures honesty utilizing limited component strategy are directed. It is normal that the undertaking will give the proposal that can enhance the execution of blower configuration base on the past investigation.

The extent of study comprises of two noteworthy parts. The first is to outline the measurement of the blower dependent on the given yield control. The outline is relied upon to be the most ideal measurement to that proposed yield.

Table 2: Different Material and Its Details

\begin{tabular}{|l|l|l|l|}
\hline Materials & Items & Parameter & Value \\
\hline $\begin{array}{l}\text { Titanium Alloy Ti-b- } \\
\text { 120UCA }\end{array}$ & Elastic Modulus & E(MPa $)$ & 0.102 E6 \\
\hline \multirow{5}{*}{$\begin{array}{l}\text { Aluminum Alloy Al- } \\
\text { a7079 }\end{array}$} & Poisson Ratio & N & 0.3 \\
\cline { 2 - 4 } & Density & $\boldsymbol{\rho}(\mathrm{kgm} 3)$ & 4850 \\
\cline { 2 - 4 } & $\begin{array}{l}\text { Ultimate Tensile } \\
\text { Strength }\end{array}$ & UTS(MPa) & 1675 \\
\cline { 2 - 4 } & Elastic Modulus & E(MPa) & $0.717 \mathrm{E5}$ \\
\cline { 2 - 4 } & Poisson Ratio & N & 0.33 \\
\cline { 2 - 4 } & Density & $\boldsymbol{\rho}(\mathrm{kgm} 3)$ & 2740 \\
\cline { 2 - 4 } & $\begin{array}{l}\text { Ultimate Tensile } \\
\text { Strength }\end{array}$ & UTS(MPa) & 558 \\
\hline \multirow{3}{*}{$\begin{array}{l}\text { Stainless Steel Alloy } \\
\text { S04 }\end{array}$} & Elastic Modulus & E(MPa) & $0.193 \mathrm{E6}$ \\
\cline { 2 - 4 } & Poisson Ratio & N & 0.29 \\
\cline { 2 - 4 } & Density & $\boldsymbol{\rho}(\mathrm{kgm} 3)$ & 8030 \\
\cline { 2 - 4 } & $\begin{array}{l}\text { Ultimate Tensile } \\
\text { Strength }\end{array}$ & UTS(MPa) & 1147 \\
\hline
\end{tabular}

\section{Meshing of the solid model}

\subsection{Element type selection}

Element types used in ANSYS may be described in terms of their shape and degree of freedom. Total number of degree of freedom gives the stiffness matrix. Common types of elements used in ANSYS are given below:

\subsection{Procedure for meshing the micro turbine}

i. Import the solid model from Pro/E and set the preferences for

ii. Structural analysis

iii. Plot the volumes obtained from the import option.

iv. Set the mesh options for the required size controls.

v. Then choose Volumes Mesh option and mesh the solid model

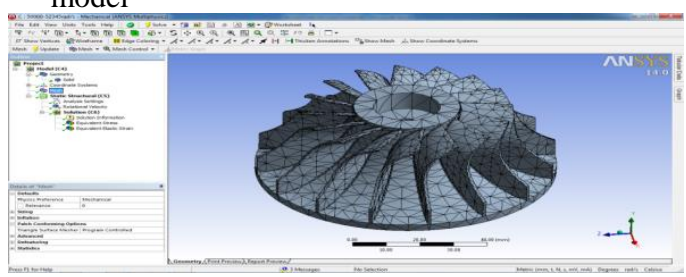

Figure 3: Meshed model of the gas turbine compressor blade

- Solid Modeling of the Piston in PRO/E

- Conversion of the solid model into finite element model

- $\quad$ ANSYS - Structural Analysis

- Applying Boundary conditions

- $\quad$ Plotting Stress Contours and Deflection Profile

\subsection{Analysis result of 4000RPM stainless steel alloy 304}

Here stainless steel alloy 304 as a material used for iteration it gives an stress distribution result at blade edges at $9.87 \mathrm{MPa}$ and blade face at $41.734 \mathrm{MPa}$ the maximum failure occurs at join between blade and turbine face is $115.38 \mathrm{MPa}$. Stainless steel alloy 304 perform almost safe strain distribution in all area of blade except the blade joints at $4000 \mathrm{rpm}$.

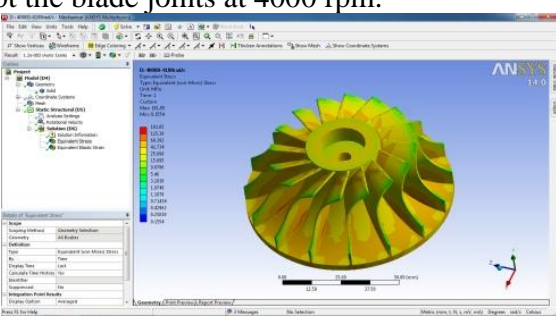

Figure 4: Stress distribution of micro turbine compressor blade

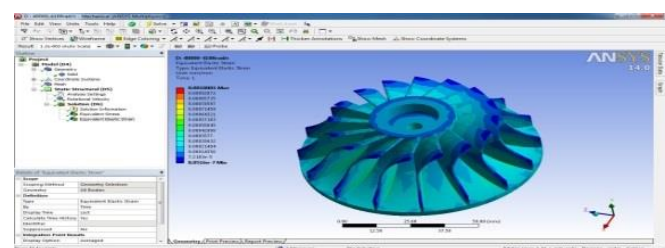

Figure 5: Strain distribution of micro turbine compressor blade

\subsection{Analysis result of $4000 \mathrm{RPM}$ aluminum alloy Al- A7079}

Here Aluminum alloy Al-A7079 as a material used for iteration it gives an stress distribution result at blade edges at 25.29MPa and blade face at $3.283 \mathrm{MPa}$ the maximum failure occurs at join between blade and turbine face is.68.751MPa. Aluminum alloyala7079 perform almost safe strain distribution in all area of Blade except the blade joints at 4000rpm.

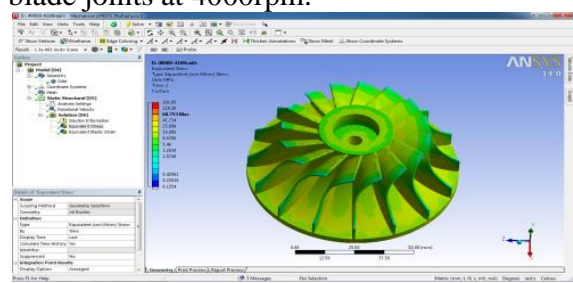

Figure 6: Stress distribution of micro turbine compressor blade

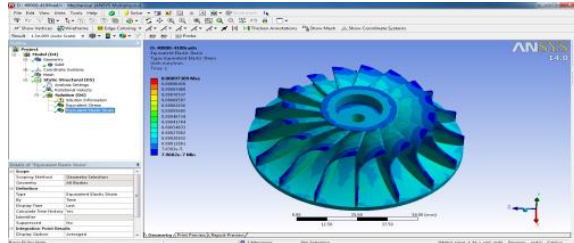

Figure 7: Strain distribution of micro turbine compressor blade

\subsection{Analysis result of 4000RPM titanium alloy TI-B- 120UCA}

Here Titanium alloy ti-b-120UCA as a material used for iteration it gives an stress distribution result at blade edges at $4.22 \mathrm{MPa}$ and blade face at $27.25 \mathrm{MPa}$ the maximum failure occurs at join between blade and turbine face is $46.76 \mathrm{MPa}$. Titanium Alloy ti-b120uca perform almost safe strain distribution in all area at 4000 rpm.

Table 3: Mechanical Properties of Blade Materials

\begin{tabular}{|l|l|l|}
\hline Material Properties & Stress $(\mathbf{M P a})$ & Deformation $(\mathbf{m m})$ \\
\hline Stainless Steel & 191.85 & 0.0010001 \\
\hline Aluminum Alloy & 68.753 & 0.00097389 \\
\hline Titanium Alloy & 115.11 & 0.0012052 \\
\hline
\end{tabular}




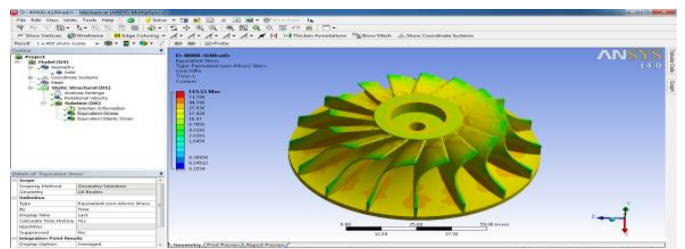

Figure 8: Stress distribution of micro turbine compressor blade

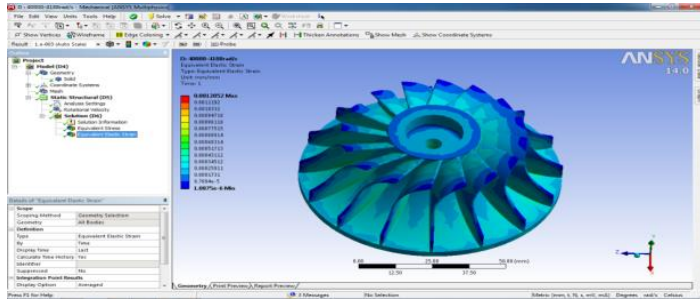

Figure 9: Strain distribution of micro turbine compressor blade

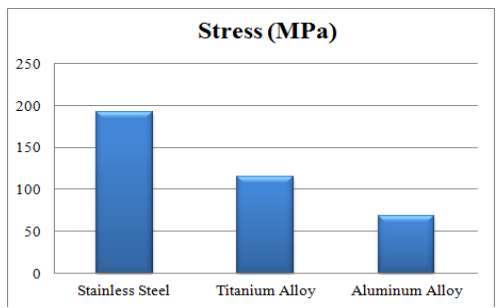

Figure 10: Stress of different blade materials @ 40000RPM

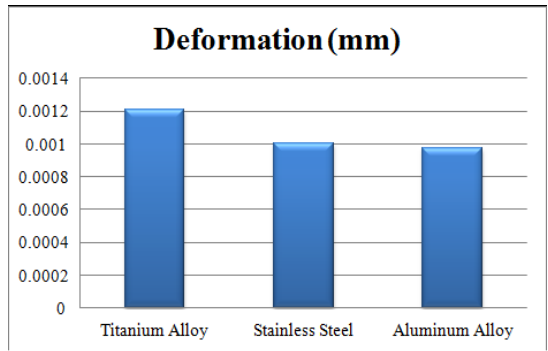

Figure 11: Deformation of different blade materials @ 40000RPM

\subsection{Analysis result of 5000RPM stainless steel alloy 304}

Here Stainless steel alloy 304 as a material used for iteration it gives an stress distribution result at blade edges at $14.17 \mathrm{MPa}$ and blade face at $45.58 \mathrm{MPa}$ the maximum failure occurs at join between blade and turbine face is $100.38 \mathrm{MPa}$.

Stainless Steel Alloy 304 perform almost safe strain distribution in compressor blade except the blade joints at $5000 \mathrm{rpm}$.

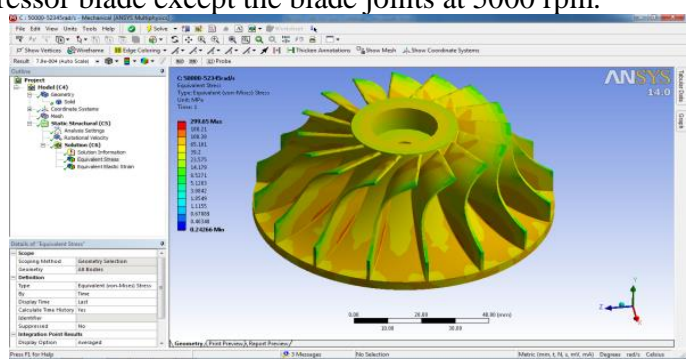

Figure 12: Stress distribution of micro turbine compressor blade

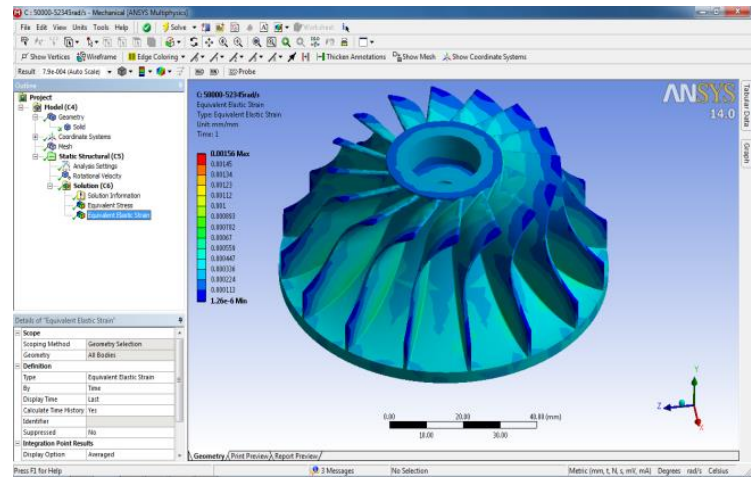

Figure 13: Strain distribution of micro turbine compressor blade

\subsection{Analysis result of 4000RPM aluminum alloy $\mathrm{Al}$ - A7079}

Here aluminum alloyal-A7079 as a material used for iteration it gives an stress distribution result at blade edges at $25.29 \mathrm{MPa}$ and blade face at $3.283 \mathrm{MPa}$ the maximum failure occurs at join between blade and turbine face is $68.751 \mathrm{MPa}$.

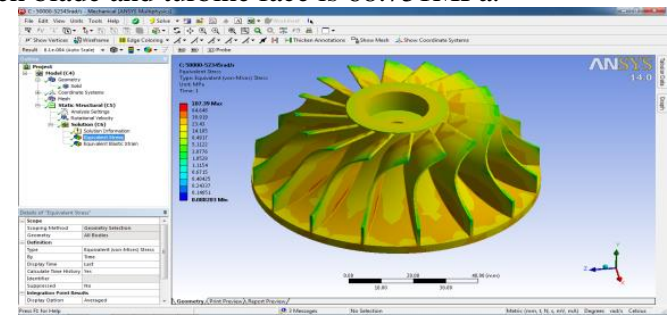

Figure 14: Stress distribution of micro turbine compressor blade

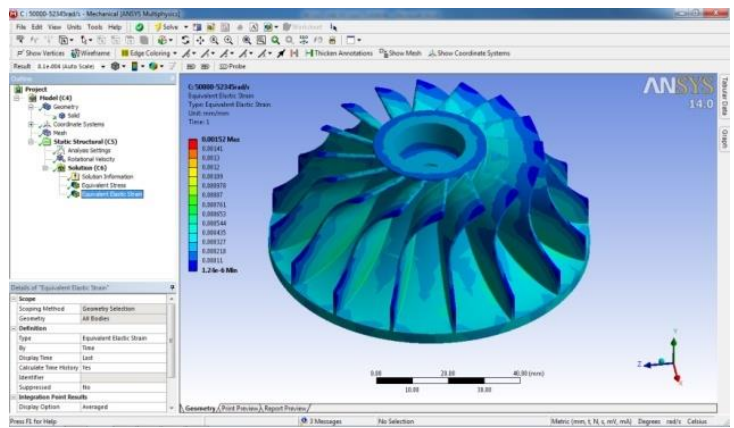

Figure 15: Strain distribution of micro turbine compressor blade

Aluminum alloy Al-A 7079 perform almost safe strain distribution in all area of Blade except the blade joints at $5000 \mathrm{rpm}$.

\subsection{Analysis result of 4000RPM titanium alloy TI-B- 120UCA}

Here Titanium alloy Ti-B-120UCA as a material used for iteration it gives an stress distribution result at blade edges at 4.22MPa and blade face at $27.25 \mathrm{MPa}$ the maximum failure occurs at join between blade and turbine face is. $66.13 \mathrm{MPa}$.

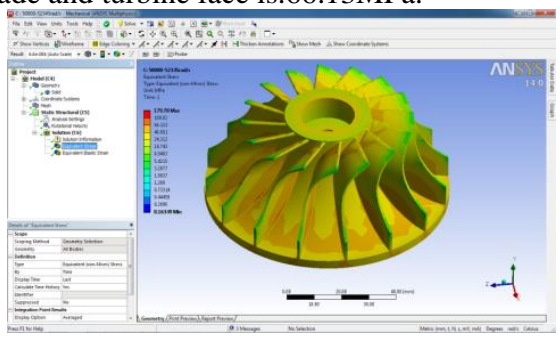

Figure 16: Stress distribution of micro turbine compressor blade 


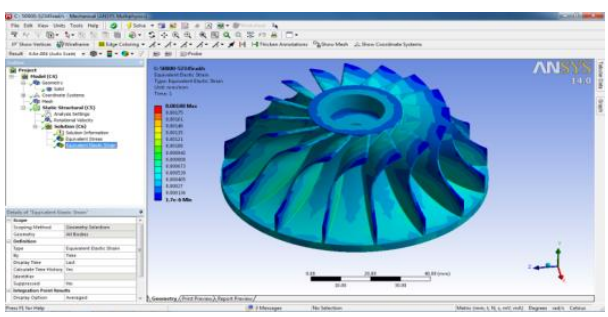

Figure 17: Strain distribution of micro turbine compressor blade Titanium alloy Ti-B-120UCA perform almost safe strain distribution in all area at 5000rpm.

Table 4: Mechanical Properties of Blade Materials

\begin{tabular}{|l|l|l|}
\hline Material Properties & Stress (MPa) & Deformation (mm) \\
\hline Stainless Steel & 299.95 & 0.00156 \\
\hline Aluminum Alloy & 107.39 & 0.00152 \\
\hline Titanium Alloy & 179.78 & 0.00188 \\
\hline
\end{tabular}

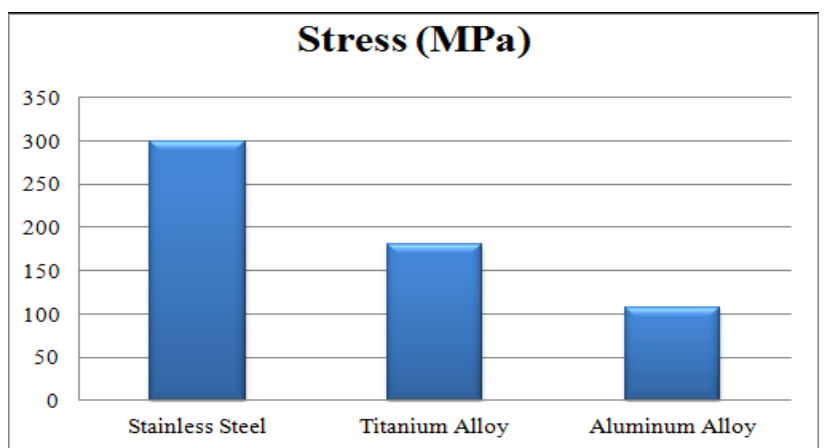

Figure 18: of Different blade materials @ 50000RPM

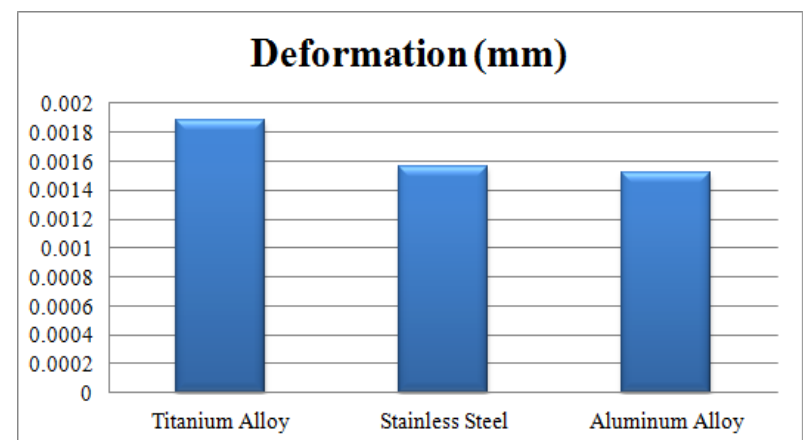

Figure 19: of Different blade materials @ 50000RPM

\subsection{Analysis result of $6000 \mathrm{RPM}$ stainless steel alloy 304}

Here stainless steel alloy 304 as a material used for iteration it gives a stress distribution result at blade edges at $12.29 \mathrm{MPa}$ and blade face at $56.49 \mathrm{MPa}$ the maximum failure occurs at join between blade and turbine face is $156.18 .38 \mathrm{MPa}$. Stainless steel alloy 304 perform almost safe strain distribution in all area of blade except the blade joints at $6000 \mathrm{rpm}$.

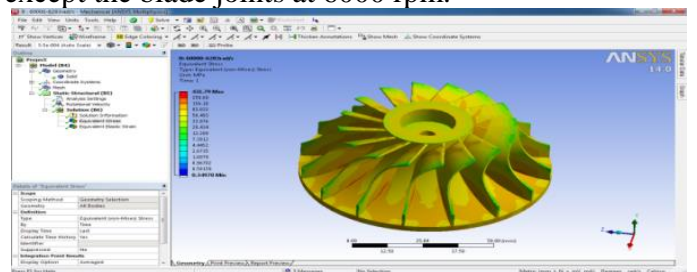

Figure 20: Stress distribution of micro turbine compressor blade

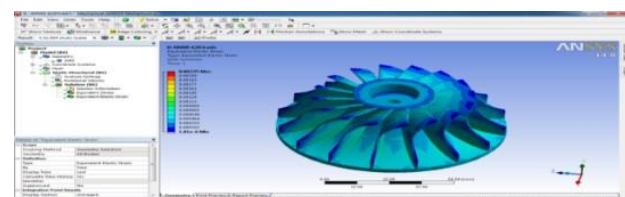

Figure 21: Strain distribution of micro turbine compressor blade

\section{Analysis result of 6000RPM aluminum alloy Al-A7079}

Here Aluminum alloy Al-A7079 as a material used for iteration it gives an stress distribution result at blade edges at $4.47 \mathrm{MPa}$ and blade face at $33.78 \mathrm{MPa}$ the maximum failure occurs at join between blade and turbine face is.56.091MPa. Aluminum alloyAlA7079 perform almost safe strain distribution in all area of blade except the blade joints at $6000 \mathrm{rpm}$.

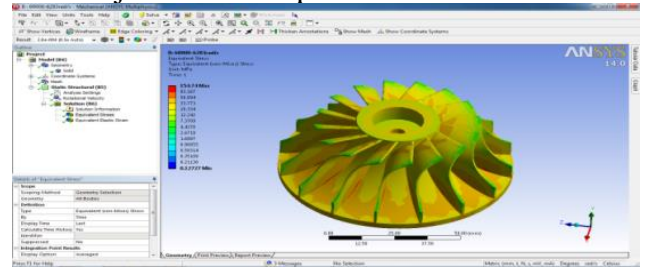

Figure 22: Stress distribution of micro turbine compressor blade

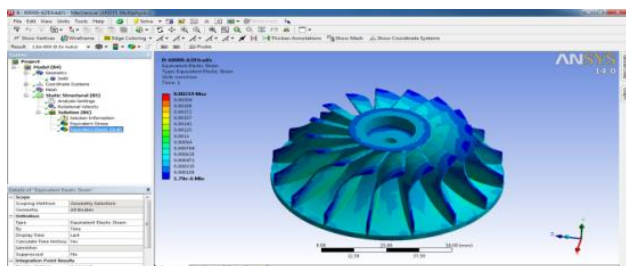

Figure 23: Strain distribution of micro turbine compressor blade

\subsection{Analysis result of 40000RPM titanium alloy TI-B- 120UCA}

Here Titanium alloy ti-b-120UCA as a material used for iteration it gives a stress distribution result at blade edges at $4.73 \mathrm{MPa}$ and blade face at $21.25 \mathrm{MPa}$ the maximum failure occurs at join between blade and turbine face is.35.251MPa. Titanium alloy ti-b120UCA perform almost safe strain distribution in all area at 6000 rpm.

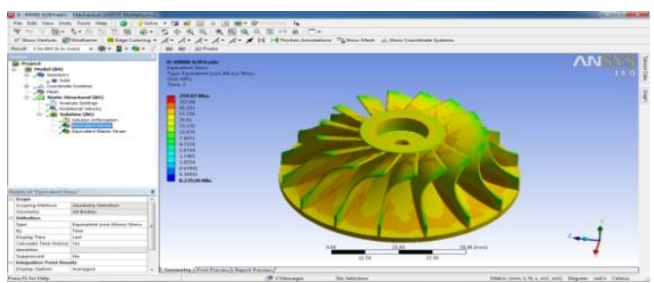

Figure 24: Stress distribution of micro turbine compressor blade

Table 5: Mechanical Properties of Blade Materials

\begin{tabular}{|l|l|l|}
\hline Material Properties & Stress $(\mathbf{M P a})$ & Deformation $\mathbf{( m m})$ \\
\hline Stainless Steel & 431.79 & 0.00225 \\
\hline Aluminum Alloy & 154.74 & 0.00219 \\
\hline Titanium Alloy & 259.07 & 0.002771 \\
\hline
\end{tabular}

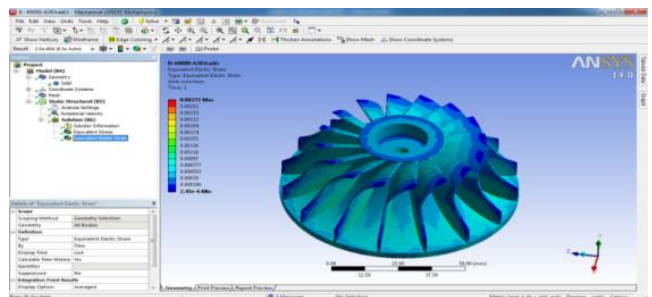

Figure 25: Strain distribution of micro turbine compressor blade 


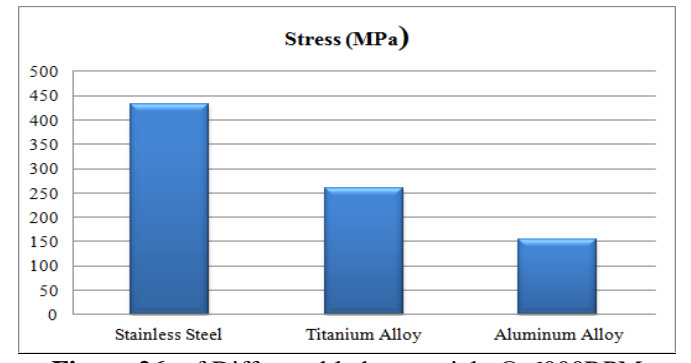

Figure 26: of Different blade materials @ 6000RPM

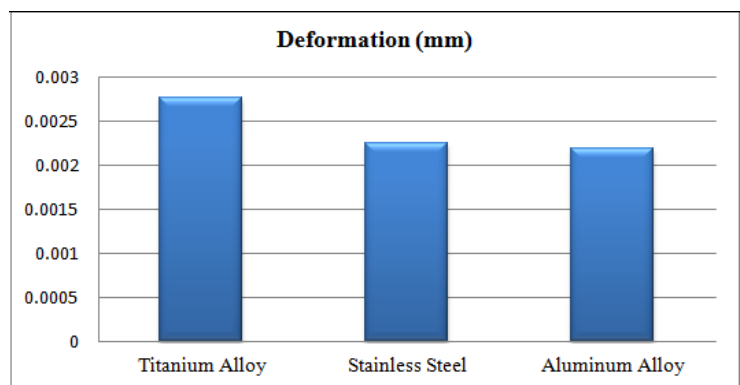

Figure 27: of Different blade materials @ 6000RPM

\section{Conclusion}

Smaller scale turbines are generally new in the market and are pulling in wide consideration because of their differed applications. Improvement of an advanced designing item like small scale turbine is a nonstop procedure. A considerable measure of work is yet to be done on the plan perspectives before the miniaturized scale turbine can be prepared for market utilization. The plan method needs to take into different parameters to make it appropriate for functional applications. From the examination we infer that the aluminum amalgam perform better in every one of the $4000 \mathrm{rpm}, 5000 \mathrm{rpm}, 6000 \mathrm{rpm}$ .so the small scale turbine blower sharp edge material is favored as Aluminum Compound A7079.

\section{References}

[1] Meherwan P. Boyce, Micro gas turbine hand book

[2] Epstein Affiliations Paper No. GT2003-38866, pp. 669-696; 28 pages, doi:10.1115/GT2003-38866

[3] Spadaccini CM, Zhang X, Cadou CP, Miki N \& Waitz IA, Gas Turbine Laboratory, Massachusetts Institute of Technology, Cambridge, MA 02139, USA Department of Manufacturing Engineering and Fraunhofer USA Center for Manufacturing Innovation, Boston University, Boston, MA 02215, USA.

[4] Energy Sources Thank-God Isaiah, Siddig Dabbashi, Dawid Bosak, Suresh Sampath, Giuseppina Di Lorenzo Pericles Pilidis Cranfield University, Building 52 Wharley End, Department of Power And Propulsion, MK43 0AL, England

[5] Félix Gauthier1, Changgu Lee2, Luc Fréchette1 1 Université de Sherbrooke, Department of Mechanical Engineering 2500 boul. Universite, Sherbrooke, QC, J1K 2R1, Canada 2 Columbia University, Department of Mechanical Engineering 220 Muddbldg, MC 4703, New York, NY 10027, USA.

[6] Henrique Cunha Department of Applied Mechanics Division of Fluid Dynamics Chalmers University of Technology Henburg, Sweden 2011 Master's Thesis 2011:43

[7] Marco Antônio Rosa do Nascimento, Lucilene de Oliveira Rodrigues, Eraldo Cruz dos Santos, Eli Eber Batista Gomes, Fagner Luis Goulart Dias, Elkin Iván Gutiérrez Velásques and Rubén Alexis Miranda CarrilloAdditional information is available at the end of the chapterhttp://dx.doi.org/10.5772/54444

[8] Rabou LPLM, Grift JM, Conradie RE, Fransen S \& Verhoeff F, "ECN Biomass, Coal and Environmental Research", PO Box 1, 1755 ZG Petten, the Netherlands 2: Cogen Projects.

[9] J. Peirs, F. Verplaetsen, D. Reynaerts Katholieke Universiteit Leuven, Department of Mechanical Engineering, Leuven, Belgium P115
[10] Tadeusz Chmielniak Sebastian Lepszy Sebastian Rulik Institute of Power Engineering and Turbomachinery Silesian University of Technology

[11] Thank-God Isaiah, Siddig Dabbashi, Dawid Bosak, Suresh Sampath, Giuseppina Di Lorenzo Pericles Pilidis

[12] Alex AE \& Nadeera M, "3D Modeling and Analysis of Micro Gas Turbine Compressor Blade”, Int. J. Mech. Eng. \& Rob. Res., Vol. 3, No. 4, (2014).

[13] Rao JS, Kishore CB \& Mahadevappa V, "Weight optimization of turbine blades", Proceedings 12th International Symposium on Transport Phenomena and Dynamics of Rotating Machinery, (2008).

[14] Lav C \& Singh RK, "CFD Analysis of an Energy Scavenging Axial Flow Micro Turbine using Automotive Exhaust Gases", International Conference of Advance Research and Innovation (ICARI), (2014).

[15] Fengxiang W, Wenpeng Z. Ming Z \& Baoguo W, "Design considerations of high-speed PM generators for micro turbines" International Conference on Proceedings. Power System Technology, Vol.1, (2002), pp.158-162. 